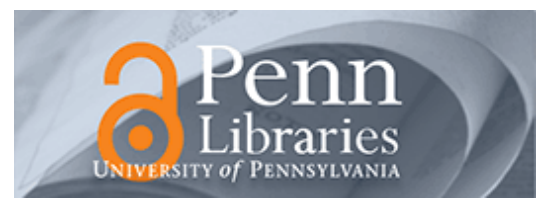

University of Pennsylvania

ScholarlyCommons

Management Papers

Wharton Faculty Research

2002

\title{
Venture-Capital Syndication: Improved Venture Selection vs. The Value-Added Hypothesis
}

James A. Brander

Raphael Amit

University of Pennsylvania

Werner Antweiler

Follow this and additional works at: https://repository.upenn.edu/mgmt_papers

Part of the Business Administration, Management, and Operations Commons, Business and Corporate Communications Commons, Corporate Finance Commons, Finance and Financial Management Commons, Management Information Systems Commons, Management Sciences and Quantitative Methods Commons, Organizational Behavior and Theory Commons, Portfolio and Security Analysis Commons, and the Strategic Management Policy Commons

\section{Recommended Citation}

Brander, J. A., Amit, R., \& Antweiler, W. (2002). Venture-Capital Syndication: Improved Venture Selection vs. The Value-Added Hypothesis. Journal of Economics \& Management Strategy, 11 (3), 423-452. http://dx.doi.org/10.1111/j.1430-9134.2002.00423.x

This paper is posted at ScholarlyCommons. https://repository.upenn.edu/mgmt_papers/309

For more information, please contact repository@pobox.upenn.edu. 


\title{
Venture-Capital Syndication: Improved Venture Selection vs. The Value-Added Hypothesis
}

\author{
Abstract \\ Syndication arises when venture capitalists jointly invest in projects. We model and test two possible \\ reasons for syndication: project selection, as an additional venture capitalist provides an informative \\ second opinion; and complementary management skills of additional venture capitalists. The central \\ question is whether venture capitalists are engaged primarily in selection or in managerial value added. \\ These alternatives imply contrasting predictions about comparative returns to syndicated and standalone \\ investments. Our empirical analysis, using Canadian data, finds that syndicated investments have higher \\ returns, favoring the value-added interpretation. We also discuss risk sharing and project scale as \\ possible reasons for syndication.

\section{Keywords} \\ venture capital, syndication, entrepreneurship

\section{Disciplines} \\ Business Administration, Management, and Operations | Business and Corporate Communications | \\ Corporate Finance | Finance and Financial Management | Management Information Systems | \\ Management Sciences and Quantitative Methods | Organizational Behavior and Theory | Portfolio and \\ Security Analysis | Strategic Management Policy
}


Venture Capital Syndication: Improved Venture Selection versus the Value-Added Hypothesis

James A. Brander, University of British Columbia, Raphael Amit, University of Pennsylvania

Werner Antweiler, University of British Columbia

February 2002

revised version

forthcoming: Journal of Economics and Management Strategy, 2002

$\begin{array}{ll}\text { Corresponding author: } & \text { James A. Brander } \\ & \text { Faculty of Commerce } \\ & \text { University of British Columbia } \\ & \text { Vancouver BC V6T 1Z2, Canada. } \\ & \text { e-mail: brander@commerce.ubc.ca }\end{array}$

Acknowledgements: James Brander and Werner Antweiler are in the Faculty of Commerce at the University of British Columbia. Raphael Amit is in the Wharton School at the University of Pennsylvania. The authors are very grateful to Mary Macdonald of Macdonald \& Associates Ltd.(www.canadavc.com) for providing access on an anonymous basis to the data used in this paper. We also thank two referees and a co-editor for very valuable comments. In addition, workshop participants at Stanford University, the University of British Columbia, and UC Berkeley have, along with other individuals, made many helpful suggestions. We would, in particular, like to acknowledge specific contributions from Keith Head, Chris Hennessy, Alan Kraus, Hayne Leland, Paul Pfleiderer, and Manju Puri. All three authors are affiliated with the W. Maurice Young Entrepreneurship and Venture Capital Centre at the University of British Columbia and are very appreciative of financial support from Social Sciences and Humanities Research Council of Canada MCRI grant no. 412-98-0025.

proposed running head: Venture capital syndication 
Venture Capital Syndication: Improved Venture Selection versus the Value-Added Hypothesis

\begin{abstract}
Syndication arises when venture capitalists jointly invest in projects. We model and test two possible reasons for syndication: project selection, as an additional venture capitalist provides an informative "second opinion"; and complementary management skills of additional venture capitalists. The central question is whether venture capitalists are engaged primarily in selection or in managerial value-added. These alternatives imply contrasting predictions about comparative returns to syndicated and stand-alone investments. Our empirical analysis, using Canadian data, finds that syndicated investments have higher returns, favoring the value-added interpretation. We also discuss risk-sharing and project scale as possible reasons for syndication.
\end{abstract}

Keywords: venture capital, syndication, entrepreneurship

JEL Classification codes: G24, M13, D83 


\section{Introduction}

One striking feature of venture capital finance is that investments are often syndicated. This means that two or more venture capitalists share in the financing of a particular venture. ${ }^{i}$ Syndication frequently occurs even when the capitalization requirements of the venture are modest compared to the financial resources of any one venture capitalist. The natural question to ask is why venture capitalists undertake syndication in such situations.

Syndication is not unique to venture capital, and also occurs with other types of investment. For that matter, any joint venture has a similar structure, as venture capital syndication is just one example of a general phenomenon in which one party to a project brings in partners. Some of the insights drawn from our analysis should therefore be quite general. However, the motives for syndication might vary from case to case, and the model structures used here are designed to represent the venture capital case. Our empirical analysis is based on information from the Canadian venture capital industry.

One rationale for syndication, suggested by Lerner (1994), is what we call the "selection hypothesis". There might be an advantage to having more than one venture capitalist evaluate a project before it is selected for investment or, in a staged ${ }^{\mathrm{ii}}$ investment setting, before additional investments are made. Syndication is a way for the first or lead venture capitalist to bring other venture capitalists into the selection process. Even after its own evaluation of a venture investment, a venture capitalist might still be

' Syndication is often taken to mean that two or more venture capitalists share a particular round of financing. Sometimes, however, the term is used more broadly to refer to situations where different venture capitalists invest in a given project at different times.

ii Venture capital financing is normally "staged" in that a venture will typically receive a modest initial investment from one or more venture capitalists, with additional investments from those (and possibly other) venture capitalists coming in subsequent stages. See Gompers (1995) for a discussion and analysis of venture capital staging based on the idea that staging is a valuable governance tool in the presence of potential agency problems. 
very unsure about the venture's prospects and might prefer to get the opinion of another venture capitalist. In effect, two (or more) independent venture capitalists might screen projects more effectively than one, because each learns something from the others' evaluation. This process could occur at the time of first investment by a venture capitalist in the firm or it could occur when additional or continuation investments are being considered by a venture capitalist. Thus syndication would lead to improved venture selection or continuation decisions.

One central objective in this paper is to provide a formal model of the selection hypothesis. Our second objective is to suggest and model an alternative hypothesis that we refer to as the "value-added hypothesis". This second hypothesis is based on the idea that venture capitalists might add value to the ventures in which they invest. Our third objective is to test empirically the relative importance of these two hypotheses. Thus our analysis addresses the general question of whether venture capitalists are primarily engaged in venture selection or whether they are primarily engaged in managerial and related activities that add value to individual ventures.

Lerner (1994) attributes the underlying idea for the selection hypothesis to Sah and Stiglitz (1986), who provide a general model of organizational design and point out that it might sometimes be preferable to have a decision process in which a project must satisfy the evaluation of two separate observers, each of whom has veto power. Sah and Stiglitz (1986) do not mention venture capital finance or any other financial sector applications and it is not obvious that their model would apply to venture capital. However, Lerner (1994) provides some data on the pattern of venture capital investments in the biotechnology sector and interprets this evidence as being consistent with the selection hypothesis.

We model the selection hypothesis as a sequential sampling problem. This model implies that returns to syndicated investments should be lower than returns to stand-alone investments. Initially, a project is brought to the lead venture capitalist for consideration. This venture capitalist assesses the project. If the estimated project quality is sufficiently low after this assessment, then the venture capitalist rejects the project outright, as there is little point in seeking a second opinion. Conversely, if the assessment yields a high expected value, then the venture capitalist accepts the project, as there is little need for a second opinion (i.e. little need for syndication) in this case either. The primary cost of 
syndicating is that the venture capitalist must share in the venture's proceeds. The venture capitalist would not want to incur this cost if a project were clearly acceptable.

The other possibility is that estimated project quality is in the intermediate range after the venture capitalist's initial assessment. It is therefore not clear whether the project should be accepted or rejected. This is the case in which a second opinion is valuable, leading the venture capitalist to pursue syndication. The most promising projects would be taken up as stand-alone investments, while projects of more moderate promise would be put in the syndication pool. This implies that stand-alone projects should, on average, yield higher returns than syndicated projects. Therefore, if improved selection is the central motivation for syndication, it follows that syndicated investments should, on average, have lower returns than stand-alone investments.

The other hypothesis we consider is the value-added hypothesis, under which venture capitalists are presumed to add value to ventures rather than simply trying to select the best ventures. From the lead venture capitalist's point of view, the benefit of seeking syndication is that the value of the project rises if other venture capitalists become involved. Different venture capitalists have heterogeneous skills and information. Some might be helpful in organizing production, others might line up customers, others might contribute in human resource management, etc. As under the selection hypothesis, the primary cost is that some share of the potentially profitable investment must be given up to secondary venture capitalists. Syndication will be sought in cases where the expected benefits exceed the expected costs of syndication. If the value-added hypothesis is correct, then observed financial returns should be higher for syndicated projects.

The implications of these two hypotheses allow a very direct test using data on returns. We have access to a database on returns to Canadian venture capital investments collected by Macdonald \& Associates. Using this data set we find that syndicated investments have significantly higher returns (in both the statistical and economic sense) than stand-alone investments. Thus our analysis favors the valueadded hypothesis over the selection hypothesis as a possible rationale for syndication. It also suggests that 
management rather than selection is at the heart of venture capitalist activity. ${ }^{\text {ii }}$

Both motives for syndication could be operating simultaneously. Therefore, our empirical results indicate that the value-added hypothesis seems more important than the selection hypothesis. In addition to the two hypotheses we formulate and test, there could also be other possible rationales for syndication. In particular, one hypothesis suggested but not tested by Lerner (1994) is the risk-sharing hypothesis. The idea is that venture capitalists undertake syndication so as to diversify their portfolios and reduce overall risk. We provide some evidence on the role of risk sharing and conclude that risk sharing may be present. A related idea is that syndication might arise from capital constraints: a venture capitalist might not have enough resources on hand to fully finance a relatively large venture. The evidence we have suggests that such constraints are unlikely to be a major explanation for syndication.

There are other possible reasons for syndication that we do not test. One possibility is collusion: by banding together rather than competing, venture capitalists might improve their bargaining position with entrepreneurs. Another possibility is that syndication has an impact on "control rights" in the venture, as the question of who controls the venture is an important consideration in venture capital finance. (See Kaplan and Strömberg (1999).) A related idea is that potential agency problems can be mitigated by syndication. In particular, Admati and Pfleiderer (1994) provide a formal model in which venture capitalists can resolve potential agency problems by maintaining a constant share of ownership in a particular venture over time. This suggests a role for syndication if other venture capitalists are sought as alternative investors.

The role of syndication in venture capital is frequently discussed in the business press and in the descriptive literature on venture capital finance. (See, for example, Kunze (1990) and Perez (1986).) However, the formal academic literature on venture capital syndication is modest in scope. Aside from

\footnotetext{
iii Gorman and Sahlman (1989) describe survey evidence on venture capital activity which suggests that venture capitalists report themselves as being actively engaged in both selection or "portfolio" activities and in managerial activities. Hellmann and Puri $(2000,2002)$ provide evidence that is consistent with the idea that venture capitalists add value through managerial activities in the venture.
} 
Lerner (1994), we are not aware of any published academic papers in which the rationale for venture capital syndication is the central focus although, as implied by previous paragraphs, some of the existing literature on venture capital finance does bear on the syndication question.

Uncertainty and information acquisition are central to our formal models, but our analysis abstracts from the "agency" perspective that has been influential in the analysis of venture capital finance. (See, for example, Amit, Brander, and Zott (1998).) We recognize that agency considerations might be relevant in explaining the motivation for venture capital syndication, as in Admati and Pleiderer (1994) and Hellman (1998), but we believe that it is also important to consider the pure learning, selection, and managerial issues that we emphasize.

Section 2 provides a brief description of the venture capital industry. Section 3 provides a formal development of the selection hypothesis, Section 4 formalizes the value-added hypothesis, Section 5 describes the data used to test these hypotheses, and Section 6 describes our econometric analysis. Section 7 provides consideration of the risk aversion and scale hypotheses, and Section 8 contains concluding remarks.

\section{A Brief Description of the Venture Capital Industry}

Unlike most other parts of the financial sector, the venture capital industry lacks a precise legal or regulatory definition. Definitions of venture capital usually focus on four characteristics. Three of these are emphasized by the following definition from Shilit (1991, p. 34): "venture capital can be thought of as financing for privately held companies, [our emphasis] generally in the form of equity [our emphasis] and/or long term convertible debt... the venture capitalist, like the banker, serves as an intermediary [our emphasis]-- or conduit -- between the investors ... and the entrepreneurs". The fourth characteristic is highlighted in the definition given by Kunze (1990): The combination of equity participation plus active involvement in the development of the company [our emphasis] is what distinguishes venture capital from all other investment vehicles."

The core activity defining venture capital is investment in privately held companies, although venture capitalists sometimes hold shares of companies even after they have gone public. The willingness to make equity investments is also a defining characteristic, and venture capitalists typically provide a 
mix of debt and equity financing. The intermediation aspect of venture capital is what distinguishes venture capitalists from wealthy individuals (often called "angels") who invest their own money in fledgling companies. The venture capitalist obtains money from arm's length investors -- often pension funds and other institutional investors, and from individuals, and pools this money with internal resources. The capacity to be actively involved in the management of young companies is also an important characteristic of venture capitalists, although this capacity is not used in all investments. Venture capitalists usually operate by setting up "funds" or partnerships, often with a fixed time horizon, and sometimes with a particular target set of investors. A single venture capitalist would typically have several funds.

Venture capital finance is a dynamic activity in that there are many stages in the financing process. The categorization of different stages is somewhat arbitrary, but it makes sense to distinguish five stages. The earliest stage is referred to as "seed" investment and may occur before a company is founded. Seed investments are often based on a single individual with an idea and relevant expertise, and the venture capitalist may assist in forming a company. The next chronological stage is start-up investment, which normally refers to investments made after a company exists but before sales occur. The next stage is the early growth phase, which corresponds to the period after the first initial sales but before sales become a major source of finance for ongoing operations. The fourth stage is referred to as "follow-on" or "mezzanine" or "later stage" financing. Finally there may be a stage of financing focussed on a specific purpose for a mature privately held company, including "turnaround" investments and "leveraged buyouts".

Within each stage there may be more than one round of investments. The amount of time associated with each stage is variable, but a horizon of about a year each would be typical for the first three stages. Later stage financing would more commonly stretch out over two or more years, and special purpose investments are usually one-time investments that might be made anytime after the first three stages are complete.

When we think of venture capital we often think of seed and start-up investment, but these stages are less important quantitatively than subsequent stages. In our data, obtained from Macdonald \& 
Associates and described in more detail in Section 5, we have fairly complete records on the venture capital investment history of Canadian companies founded in 1990 or later that ultimately received venture capital finance from Canadian venture capitalists. In this population, a few (1\%) received their first venture capital investment in the calendar year preceding founding of the company. These are definitely seed investments. A further $21 \%$ received their first investment in the same calendar year that the venture company was founded. These would be a mixture of seed and start-up investments. Another $10 \%$ received their first investment in the calendar year subsequent to founding. This would include some investments that would qualify as start-up investments and some that would be early growth stage investments. An additional 7\% of ventures received their first investment in the second calendar year subsequent to being founded. The median time from founding to first venture capital investment is between three and four years.

Syndication, if it occurs, normally occurs soon after the first venture capital investment. Specifically, of those ventures that received investments from more than one venture capitalist, about $70 \%$ received an investment from a second venture capitalist within the same calendar year as the initial investment by the lead venture capitalist. We can think of three major patterns for syndicated investments. The most common pattern is that first investment from a venture capitalist occurs in the early growth stage or later, with syndication occurring simultaneously or shortly after. The second pattern is that the lead venture capitalist makes a seed or start-up investment, followed by syndication at a later stage. In such cases the experience of the lead venture capitalist will influence future investments, as a poor outcome at the seed or start-up phase (as judged by the lead venture capitalist) may lead to termination of the venture. The third and least common pattern is that syndication occurs at the seed or start-up stage. Under all patterns the lead venture capitalist is the primary decision-maker over whether syndication occurs.

\section{FIGURE 1 HERE}

As illustrated in Figure 1, one other important feature of venture capital finance in Canada over the sample period is that the amount of venture capital finance increased with time, as did syndication. In Figure 1 the bars show the share of all new venture capital investments in a given year that are syndicated 
in the (narrow) sense that two or more venture capitalists invest in a given venture in the same calendar year. Thus, in 1992 about $40 \%$ of all new investments were components in syndicated projects. The line shows the total number of new venture capital investments.

\section{A Formal Model of the Selection Hypothesis}

We construct the simplest model we can that allows rigorous formulation of our research question. ${ }^{\text {iv }}$ We assume that a project or venture arrives at time $t_{1}$ for consideration by a lead venture capitalist. We assume, without loss of generality, that the project has a required investment of 1 . The project will yield a (non-negative) cash flow. If this cash flow is zero, then the entire investment is lost. The venture capitalist's problem is to investigate the project and decide whether to accept it or reject it.

This investigation consists of independent "trials", each of which yields a "signal". The signal is binary in that it can take on only two possible values: positive (good) or negative (bad). We can then write the expected cash flow from the venture as $R(j, N)$, where $j$ is the number of positive signals and $N$ is the number of trials. Each signal is assumed to be informative as defined by the following conditions.

$$
R(j+1, N)>R(j, N)
$$

and

$$
R(j, N)>R(j, N+1)
$$

Condition (1) states that expected cash flows are higher if there are more positive signals in a given number of trials. Condition (2) states that expected cash flows decrease if it takes more trials to get a given number of positive signals. These conditions are precisely what we mean in assuming that the signals are informative. The simplest information structure that allows for the different information states we require is to assume that the venture capitalist's investigation is equivalent to two trials. This allows the information to be good (two positive signals), bad (two negative signals), or intermediate (one signal of each type).

At time $t_{2}$ the venture capitalist chooses among three possible actions: outright rejection, outright

\footnotetext{
iv We are particularly grateful to a referee for indicating how to provide a simpler and more general representation of the selection hypothesis than in our original formulation.
} 
acceptance, and "seeking syndication". If the venture capitalist seeks syndication, then additional venture capitalists are approached. These secondary venture capitalists evaluate the project and provide a recommendation to accept or reject. This evaluation is treated as a third trial and the recommendation as a third "signal" for the lead venture capitalist, who then makes a final decision to accept the project as a syndicated project or to reject it. An implicit assumption is that the lead venture capitalist cannot simply purchase (at relevant cost) an extra signal from a consultant or outside source. To get the extra information it is necessary to seek syndication. Figure 2 illustrates this decision-making sequence.

\section{FIGURE 2 HERE}

To explain syndication we need to analyze the decision node that occurs at time $t_{2}$. We assume that the venture capitalist is risk-neutral and thus seeks the action with the highest expected value. If the venture capitalist rejects the project then available funds are placed in an alternative investment. We define $\mathrm{r}$ as the expected gross cash flow per unit investment in this alternative. If the project goes ahead under syndication, the lead venture capitalist provides (exogenous) share " < 1 of the required investment, with the rest being provided by the other syndicating venture capitalists. The amount (1-") that the lead venture capitalist has left over out of the original potential investment is invested in the alternative asset and will therefore return expected cash flow (1-")r.

The lead venture capitalist maximizes expected value and will therefore compare the expected value from the three possible actions at time 2 and will select the action with the highest expected value. We impose the following structural assumption on the expected returns to insure that rejection, acceptance and syndication are all feasible possibilities.

$$
\mathrm{R}(1,2)<\mathrm{r}<\mathrm{R}(2,3)
$$

$\mathrm{R}(1,2)$ is the expected return from one positive signal out of two trials. This is assumed to be less than the alternative investment value, r. On the other hand, the expected return from two positive signals out of three trials exceeds this alternative. We now state the main properties of the model in the form of propositions. 


\section{Proposition 1:}

i) The lead venture capitalist will reject the project outright if the initial two signals are negative.

ii) The lead venture capitalist will accept the project outright if the initial two signals are positive.

iii) The lead venture capitalist will seek syndication if the two initial signals differ in sign.

Proof:

i) If the two initial signals are negative, the expected return under outright acceptance is $R(0,2)$, whereas the expected return under outright rejection (and consequent investment in the alternative) is $r$. Using (1) and (4), $\mathrm{R}(0,2)<\mathrm{R}(1,2)<\mathrm{r}$, so outright rejection dominates outright acceptance. In addition, rejection dominates seeking syndication. If syndication is sought, the best possible expected return to the project after trial 3 is $\mathrm{R}(1,3)$. Under syndication the lead venture capitalist's expected value after trial 3 would be " $\mathrm{R}(1,3)+(1-") r$, where " $<1$. This must be less than $\mathrm{r}$ as (2) and (4) imply that $\mathrm{R}(1,3)<\mathrm{R}(1,2)<\mathrm{r}$. Thus, after two initial negative signals, rejection dominates even the best possible outcome under the syndication option. ${ }^{\mathrm{v}}$

ii) The expected return from outright acceptance after two initial positive signals is $R(2,2)$. From (1), (2) and (4) it follows that $\mathrm{R}(2,2)>\mathrm{R}(2,3)>\mathrm{r}$, which implies that outright acceptance dominates outright rejection. Syndicated acceptance also dominates rejection, but syndication merely dilutes whatever return arises, as the lead venture capitalist would receive only share " $<1$ of this return. Outright acceptance is therefore preferred.

iii) If the two initial signals differ, it follows from (4) that the lead venture capitalist would not accept the project outright as $\mathrm{R}(1,2)<\mathrm{r}$. However, the project would be worthwhile if the potential syndicating partners were positive (i.e. if the third signal were positive) as $\mathrm{R}(2,3)>\mathrm{r}$. Therefore, seeking syndication dominates outright rejection, as the lead venture capitalist will either end up rejecting anyway, and will

\footnotetext{
$\checkmark$ The lead venture capitalist could always reject after considering syndication, in which case seeking syndication would be equivalent to outright rejection. We break this "tie" in favour of outright rejection on the grounds that if we incorporated even slight concessions to additional realism such as discounting or transaction costs, then outright rejection would be strictly preferred.
} 
still receive return $\mathrm{r}$, or will accept part of a syndicated project with an expected return exceeding $\mathrm{r}$. *** Proposition 2: Syndicated projects will be lower in expected value than stand-alone projects. Therefore, observed syndicated projects should have a lower average return than observed stand-alone projects. Proof: From Proposition (1) we infer that stand-alone accepted projects have expected return R(2,2), whereas syndicated projects have expected return $R(2,3)$. It follows from expression $(2)$ that $R(2,2)>$ $\mathrm{R}(2,3)$. ***

The logic of Proposition 2 is that high quality projects are more likely to yield two initial positive signals and are therefore more likely to be accepted outright than lower quality projects. Conversely, intermediate quality projects are more likely to generate an intermediate initial information pattern and are therefore more likely to be considered for syndication. ${ }^{\mathrm{vi}}$

\section{The Value-Added Hypothesis}

The idea underlying the value-added hypothesis is that the lead venture capitalist seeks syndication to enhance the performance of the venture. This contrasts with the selection hypothesis, under which syndication helps to select the best projects but does not affect the performance of any venture. As in the selection model, we assume that a representative venture or project requires capitalization normalized to 1 and that the expected cash flow or payoff is R. We need to abstract from the selection problem considered in the previous model, so we assume that $\mathrm{R}$ is known unconditionally and is not affected by learning.

As before, there are alternative investments available that return expected cash flow $r$. If $R>r$, then stand-alone acceptance would be preferred to rejection. Assuming, as before, that "ties" are decided in favour of rejection, if $r \$ R$ then rejection is preferred to stand-alone acceptance. Under the value-added

\footnotetext{
vi Other structures with more ambiguous outcomes are possible. For example, if new ventures are immediately identified by the lead venture capitalist as coming from one of two distributions - one of which has a high mean and a high variance, then syndication (i.e. more information) might be sought in high mean - high variance cases. However, the structure underlying Propositions 1 and 2 seems to capture the central insight regarding selection effects.
} 
model, syndication increases the expected return of some projects. The value added to the project from syndication is denoted $\mathrm{N}$. The expected payoff if the project is syndicated is therefore $\mathrm{R}+\mathrm{N}$. A project might not benefit at all from syndication or it might benefit substantially. To keep the analysis simple we assume that $\mathrm{N}$ can take on only two possible values: $\mathrm{v}$ or 0 .

$$
\begin{aligned}
\mathrm{N} & =\mathrm{v} & & \text { with probability } \mathrm{B} \\
& =0 & & \text { with probability }(1-\mathrm{B})
\end{aligned}
$$

As before, if syndication occurs, the lead venture capitalist takes on fraction " of the project, and therefore invests only " in the project, with (1-") being invested in the outside alternative. As the outside alternative returns cash flow $r$ per unit invested, an investment of (1-" ) returns cash flow (1-")r. We assume that $\mathrm{v}$ is large enough to make syndication attractive relative to stand-alone investment. Defining $\mathrm{R}^{*}$ as the upper bound on the expected value of a stand-alone project, we therefore require the following condition:

$$
\mathrm{v}>\left(\mathrm{R}^{*}-\mathrm{r}\right)(1-") / "
$$

As in the selection model, the lead venture capitalist chooses to reject the project (action 1), accept the project on a stand-alone basis (action 2) or seek syndication (action 3). This choice is made after observing N. In this model, syndication will always occur if the lead venture capitalist chooses action 3. It is useful to form the differences between the expected values. Using $*_{\mathrm{ij}}$ to represent the difference between the expected value of actions $i$ and $j$, we can write the following.

$$
\begin{aligned}
& *_{21}=\mathrm{R}-\mathrm{r} \\
& *_{31}="(\mathrm{R}+\mathrm{N})+(1-") \mathrm{r}-\mathrm{r}="[\mathrm{R}-\mathrm{r}+\mathrm{N}] \\
& *_{32}="(\mathrm{R}+\mathrm{N})+(1-") \mathrm{r}-\mathrm{R}=" \mathrm{~N}-(1-")(\mathrm{R}-\mathrm{r})
\end{aligned}
$$

In practice $\mathrm{R}$ and $\mathrm{N}$ might be correlated, but we make the inessential and algebraically convenient assumption that $\mathrm{R}$ and $\mathrm{N}$ are independent: the value-added of syndication does not depend on the underlying project quality. Proposition 3 states the conditions under which stand-alone investment, syndication, and project rejection will be chosen.

\section{Proposition 3:}

i) Stand-alone investment will be chosen if and only if $\mathrm{R}>\mathrm{r}$ and $\mathrm{N}=0$. 
ii) Syndication will be chosen if and only if $\mathrm{N}=\mathrm{v}$ and $\mathrm{R}>\mathrm{r}-\mathrm{v}$.

iii) Rejection will be chosen if and only if i) $\mathrm{N}=0$ and 2 \#r, or ii) $\mathrm{N}=\mathrm{v}$ and $\mathrm{R} \# \mathrm{r}-\mathrm{v}$.

\section{Proof: See Appendix}

We can see from Proposition 3 that syndication hinges, as we would expect, on the project being one for which syndication actually provides value-added. Otherwise, either rejection or stand-alone investment would be preferred. Proposition 3 indicates that $\mathrm{v}$ is large enough relative to $\mathrm{R}^{*}$ that syndication is preferred to stand-alone investment for those situations where syndication adds value. The lead venture capitalist would not choose to "cherry pick" the very best projects for stand-alone investment.

In order to compare the expected returns to syndicated and stand-alone investments it is necessary to make some distributional assumptions about $\mathrm{R}$. We assume that $\mathrm{R}$ is uniform on the interval $\left[0, \mathrm{R}^{*}\right]$. We take this as a neutral case and it has the advantage of providing computational simplicity. Recall that $\mathrm{R}$ is the expected value, not the realized value. Realized values are highly skewed, but expected values are based on a high level of ignorance and might perhaps be taken as uniform.

Proposition 4: The expected rate of return to syndication exceeds the expected rate of return to standalone investment.

Proof: See Appendix. ***

It might seem obvious that average returns from syndication will exceed average returns from stand-alone investment as venture capital firms will seek to syndicate in precisely those cases where syndication has high value-added. However, adding value through syndication might allow a project that would fail the stand-alone standard to be accepted for syndication. This might tend to lower the return of syndicated projects relative to stand-alone projects. The relative importance of this effect depends on ", on the correlation between $\mathrm{N}$ and $\mathrm{R}$, and on the distribution of $\mathrm{R}$.

The role of " arises because syndication has a cost to the lead venture capitalist in that the project must be shared. This cost will be borne only for those projects that yield a sufficiently high value-added from syndication. This is the key effect that tends to make the aggregate return to syndicated projects higher, and this effect is stronger if " (the lead venture capitalist's share under syndication) is smaller. 
Second, we have assumed that the value from syndication, $N$, is uncorrelated with the intrinsic quality of the project as reflected by R. Alternatively, if we made the plausible assumption that $\mathrm{N}$ were positively correlated with $\mathrm{R}$, then this would also tend to make syndicated projects have a higher return than standalone projects as the very good projects would tend to be those that also offered high returns from syndication. Therefore, the assumption that $\mathrm{N}$ is additive and uncorrelated is conservative. The distribution of $\mathrm{R}$ is relevant as we need to rule out the possibility that adding $\mathrm{v}$ in an uncorrelated way to expected value R moves a large mass of the expected value distribution from being unacceptable to being marginally acceptable under syndication. This would seem an unlikely possibility that would be ruled out by many alternative reasonable assumptions. The uniform distribution is simple and sufficient, and should be regarded as an illustrative example.

\section{Data}

The two models presented in Sections 2 and 3 have strikingly different implications for the pattern of returns to venture capital investments. The selection hypothesis implies that syndicated investments should have lower rates of return than stand-alone investments. Conversely, the value-added hypothesis suggests that syndicated investments should have higher expected rates of return than standalone investments. To test the relative empirical strength of these hypotheses we therefore need data on returns to venture capital investments.

The data used for this study were collected by Macdonald \& Associates and made available to us on an anonymous and confidential basis. In addition, no specific information related to a single firm venture or venture capitalist - is reported or discussed. The data are derived from several surveys conducted by Macdonald \& Associates. The most important survey for our purposes is the "exit survey" which records information about the divestiture of venture capitalist investments for the period from 1992 through 1997, plus the first quarter of 1998. These divestments or "exits" can occur in several ways. For unsuccessful ventures, the venture capitalist might "exit" simply by writing off the investment. For more successful ventures, the venture capitalist might exit by selling its shares to a third party as part of a private third party acquisition. If the venture "goes public" in an initial public offering (IPO) and the venture capitalist subsequently sells its holding, this is recorded as an IPO. There are three other types of 
exit in the data. One type is the management buyout (MBO), in which the venture capitalist sells its share to managers or officers of the venture itself. Another type of exit is the secondary sale in which the venture capitalist's holding is sold in a private sale to a third party, but not as part of an overall third party acquisition. The other type of exit is "other" which simply means that the exit vehicle was not reported. There are 584 exits in the data, including partial exits in which some but not all of the venture capitalist's holding is divested. Figure 3 shows the distribution of exit by exit vehicle.

\section{FIGURE 3 HERE}

The exit survey records the value of the venture capitalist's divestment. It also records the cost of obtaining the investment in the first place. Thus, for example, the venture capitalist might acquire a block of shares for \$1 million and subsequently sell the block of shares for \$2 million. The apparent nominal return would then be $100 \%$. It is, of course, important to know the holding period of the investment so that an annualized rate of return can be calculated. Unfortunately, the holding period is not reported directly in the exit survey. It can, however, be inferred in principle from a related survey carried out by Macdonald \& Associates referred to as the "investment survey" which tracks the timing of investments made by the venture capitalists. We say "in principle" because full prior investment information is not available for all exits. Of the 584 total exits, we can calculate holding periods for 393 and can therefore calculate annualized (real) rates of return. For the other 191 exits, we know the aggregate nominal return but not the holding period.

It is possible to estimate the holding period for these investments using other characteristics of the data. For the data with known holding periods we form a regression equation that "explains" the holding period. The explanatory variables for this regression are industry, location, the investment round, and exit vehicle. This regression equation can then be used to predict the holding period for those observations where it is missing. The predicted holding periods ${ }^{\mathrm{vii}}$, while noisy, contain some useful information in the

\footnotetext{
vii The holding period regressions have only a modest corrected $\mathrm{R}^{2}$ of 0.19 . The location variables include dummy variables for Quebec and the West, with the base being the rest (mostly Ontario). The industry dummy variables are manufacturing, biotech, and computers and communications, with the base being the
} 
sense that a significant part of the variation in estimated returns is due to actual variation in annualized returns, and the rest of variation can be viewed as "noise". Restricting attention to just the 393 observations with known holding periods would involve "wasting" the information contained in the investment cost and value information for the other exits. We therefore consider the extended 584observation data set as well as the smaller 393-observation data set. We refer to these as the "extended" and "primary" data sets respectively. We report results for both data sets, although we put the main emphasis on the primary data set.

Macdonald \& Associates seek to track all venture capital investments in Canada made by Canadian venture capitalists. While coverage is not complete, information is obtained on the vast majority of such investments. Fortunately for our purposes, the data contain information on syndication. Thus, for each exit made by a venture capitalist, we know if other venture capitalists also had investments in that venture, and we know, in most cases, when that investment occurred.

The unit of observation for the analysis in subsequent sections is the completed venture capital investment. (In contrast, the data described in Section 2 is based on all venture capital investments, not just completed investments.) For example, venture capitalist A might make an investment in firm 1, and get shares in the firm in return. At some future time, this investment might be sold, and a rate of return can be calculated. This record would form one observation in the data set used for subsequent sections. Venture capitalist B might also make an investment in firm 1 and might subsequently sell its share as well. This investment would be a second observation. Note that the rate of return to venture capitalist B could be quite different from the rate of return to venture capitalist A for investments in the same venture. In addition, venture capitalist $\mathrm{C}$ might also invest in firm 1, but might not have sold its share by the time of the latest survey in the dataset. This investment by venture capitalist $\mathrm{C}$ would not be recorded as a completed investment and would therefore not be a record or observation in our data set.

rest. The exit dummies are as shown in Figure 3. We also use an activity counter associated with an exit. Any investment or exit counts, so if an exit has a count of, say 5 , this would mean that the exit was the $5^{\text {th }}$ recorded investment or exit event for this venture. Holding periods are increasing in this variable. 
There are two possible definitions of syndication (as described in footnote 1). The "narrow" definition would imply that syndication occurs when two venture capitalists make investments simultaneously. The broader definition would allow investments to count as syndicated investments regardless of whether the investments occurred at the same or different times. Operationally, if investments by different venture capitalists occur in the same calendar year, we treat this as satisfying the narrow definition. Broadly defined syndication occurs if a second venture capitalist invests in the venture at any time, provided there is some overlap among venture capitalists in time.

One potential difficulty is that venture capitalist A might make an investment, fully exit at a later time, followed, at a still later time, by an investment from venture capitalist B. Such a situation should not be viewed as syndication. However, if these three steps: investment by A, full exit by A, and entry by B all occurred in one calendar year, this would mistakenly count as a syndicated investment in the narrow sense. This is at most a very small problem in our data. Of 171 narrowly syndicated investments, only 10 have an investment and exit by the same firm in the same year, and most of these can determined to be genuine syndications by carefully inspecting the data. We believe that at most one or two cases would be false syndications.

For the broad definition of syndication, "false positives" could potentially be a problem. Exits are observed from the first quarter of 1992 through the first quarter of 1998 so this does give time for full exit by one venture capitalist and subsequent investment by another. We address this problem as follows.

First we take all narrow syndications. Then we add all situations where a second venture capitalist entered in a calendar year subsequent to the first venture capitalist's investment. We then remove all cases where the first venture capitalist had an exit in a prior year to the second venture capitalist's investment. This will unfortunately eliminate cases where the first venture capitalist only sells part of its holding before the second venture capitalist joins. We therefore add back those cases where the first venture capitalist has another exit following second venture capitalist's investment, as this indicates that overlap did occur. Overall, the broad syndication variable should be a reliable indicator of overlapping investment by venture capitalists.

There are 171 (out of 584) narrow syndications in the extended data set and 147 (out of 393) in 
the primary data set. Using the broader definition of syndication, there are 243 (out of 584) syndicated investments in the extended data set and 194 (out of 393) in the primary data set. Even though broad syndications cover a much larger period (6 years) than narrow syndications ( 1 year), moving from narrow to broad increases the number of syndications by only about $30 \%$ in the primary database and about $40 \%$ in the extended database. We report results for both the narrow and broad definitions of syndication.

Our data does not track syndication attempts that do not yield syndication. Therefore, we cannot observe cases of syndication giving a "bad signal.". This does not compromise the statistical tests we carry out. The quality and nature of the data we have is, to our knowledge, unique and allows more direct evaluation of the rationale for syndication than has previously been possible.

\section{Estimation and Results:}

The empirical test is straightforward in principle. We wish to see whether syndicated or standalone investments have higher returns. We use two approaches. First we compare the mean returns of the two classes of investment. We also use regression analysis. The "rate of return" is the annualized arithmetic (or simple) real rate of return. ${ }^{\text {viii }}$ The overall average simple real return is $24.5 \%$ per year. The corresponding portfolio return is $16.3 \%$ per year. (This is, in effect, the average return weighted by investment size.)

\subsection{Using t-tests to Evaluate Differences in Average Returns}

Table 1 reports t-tests of the null hypothesis that the mean rates of return for syndicated

\footnotetext{
viii We use the arithmetic (simple) rate of return rather than the geometric (compounded) rate because the arithmetic rate allows a much more satisfactory treatment of write-offs, which represent a significant share of the data set. If a write-off occurs, then the geometric rate of return is $-100 \%$ per year, regardless of the holding period. Thus, for example, if a 1 million dollar investment is written off to 0 after 4 years, the only way this can occur under geometric compounding is if the loss in the first year is $-100 \%$. Any rate of return less (in absolute value) than 100\% would imply that something must be left after 4 years. The arithmetic rate of return is simply $-25 \%$ per year, which is much more likely to approximate the actual loss in value.
} 
investments and stand-alone investments are the same against the (two-sided) alternative that they differ, carried out under the presumption of unequal variances. In the row reporting estimated differences, standard errors are reported in square brackets. Two asterisks indicate significance at the $5 \%$ level or better.

Table 1: Annual Rate of Return Differences for Syndicated and Stand-Alone Investments

\begin{tabular}{|c|c|c|c|c|}
\hline Data Set & primary, narrow & primary, broad & extended, narrow & extended, broad \\
\hline Stand-Alone: $\mu_{1}$ & 17.4 & 14.9 & 20.3 & 17 \\
\hline Syndicated: $\mu_{2}$ & 39 & 36.5 & 34.8 & 35.3 \\
\hline Diff.: $\mu_{2}-\mu_{1}$ [st. err.] & $21.6[9.3]$ & $21.7[9.0]$ & $14.5[8.12]$ & $18.3[7.49]$ \\
\hline t-stat: $\mathrm{H}_{\mathrm{a}}: \mu_{1} \ldots \mu_{2}$ [p-val.] & $2.09[.038]^{* *}$ & $2.40[.017]^{* *}$ & $1.60[.111]$ & $2.35[.019]^{* *}$ \\
\hline$\#$ of observations & 393 & 393 & 584 & 584 \\
\hline
\end{tabular}

Table 1 shows that the syndicated investments had substantially higher average returns for all four data classifications than the stand-alone investments. The absolute difference in rates of return is large, as stand-alone investments had average rates on the order of 15 to 20 percent, whereas the syndicated investments had average returns of about 35 to 39 percent. Because of the underlying variability in rates of return and the modest sample sizes, the t-statistics are not particularly large, but they are significant at the $5 \%$ level for three of the four classifications, including the "primary, narrow" case, which we take as the most important. The significance levels are with respect to the two-sided alternative that the two groups of investments have different means. If we consider the one-sided alternative that syndicated investments have a higher mean return, then the significance levels would be stronger (i.e. smaller), and even the "extended, narrow" case would allow rejection of the null hypothesis at better than the $10 \%$ significance level.

Therefore, if we treat the data set as a sample, we would reject the null hypothesis of equality in favor of the alternative that the syndicated investments have higher returns. Arguably, however, we might treat the data sets as a population rather than a sample, in which case we would simply observe that the syndicated investment in fact have much larger returns on average than the stand-alone investments. 
The means tests show a clear and striking pattern. Even though the distributions of returns for stand-alone and syndicated investments overlap, as implied by the standard errors, the differences in average returns are so great that we might wonder if some sort of selection bias could be present. One type of selection bias that might seem plausible is that syndication partners seek to sign on with successful ventures after observing early signs of success.

This effect is sometimes called "window dressing", as venture capitalists try to make themselves look good by becoming associated with successful ventures. Presumably the secondary partners in such syndications would earn only normal returns, but the lead venture capitalist would earn large returns and this would be enough to bias the returns. If this is true, however, it should apply more forcefully to the broadly-defined syndications, and should not really apply to the narrowly defined syndications, which take place within the same year, and which normally occur well before returns are realized. Looking at the primary data set, however, we see that the differences in average returns are nearly the same for narrowly defined syndications as for broad, suggesting that this selection bias is either absent or very modest. Also, the mere fact that most syndications are narrow suggests that not many venture capitalists are joining late. More formal (regression) analysis shows no significant effect of time between investments on returns. Overall, we see little or no evidence of "window dressing” in our data.

\subsection{Using Regression Analysis to Evaluate Differences in Returns}

It is possible that the pattern found in section 6.1 might be induced by a failure to correct for other relevant factors. Perhaps, for example, some industries differentially attract syndication and also have higher returns. We do have several variables in the data set that we might wish to correct for in a regression analysis. In particular, each exit is associated with one of six industries: computing and communications, electrical components, manufacturing, biomedical and pharmaceuticals, other healthrelated, and other. A dummy variable for the computing and communications sector is significant as an explanatory variable for returns while the other industries are not significant. More precisely, the returns to the computing and communications (COMP) sector are significantly different from the returns to the 
aggregate of the other sectors while the other sectors are not significantly different from one another. ${ }^{\mathrm{ix}}$ One other important explanatory variable is PTS, which stands for "preferential tax status". Some venture capital funds enjoy preferential tax status that allows them to raise money more cheaply than other funds. This leads to an overall explanatory regression for the rate of return of the following form:

$$
\text { r.o.r. }=\$ 0+\$ 1 \mathrm{SYN}+\$ 2 \mathrm{PTS}+\${ }_{3} \mathrm{COMP}+
$$

where SYN is a dummy variable that takes on the value 1 for syndicated investments and 0 for standalone investments. The variables PTS and COMP are also dummy variables.

Table 2: Regression Results

Dependent variable $=$ Annual $\%$ rate of return; Syndication $=$ dummy variable

\begin{tabular}{||c|c|c|c|c||}
\hline data set & primary, narrow & primary, broad & extended, narrow & extended, broad \\
\hline syndication & $19.6(2.13)^{* *}$ & $18.1(2.02)^{* *}$ & $11.0(1.37)$ & $13.2(1.76)^{*}$ \\
\hline computer industry & $23.9\left(2.35^{* *}\right)$ & $21.8(2.13)^{* *}$ & $26.7(3.17)^{* * *}$ & $24.8(2.92)^{* * *}$ \\
\hline pref. tax status & $-28.4\left(2.02^{* *}\right)$ & $-29.3(2.08)^{* *}$ & $-31.1(3.20)^{* * *}$ & $-31.2(3.22)^{* * *}$ \\
\hline const & $15.1(2.31)^{* *}$ & $14.2(2.06)^{* *}$ & $20.0(3.88)^{* * *}$ & $18.2(3.40)^{* * *}$ \\
\hline \# obs & 393 & 393 & 584 & 584 \\
\hline adj. $\mathrm{R}^{2}$ & 0.04 & 0.04 & 0.04 & 0.04 \\
\hline
\end{tabular}

t-statistics are in parentheses. $* * *$ represents a p-value of .01 or less, $* *$ represents a p-value between .01 and .05 , and * represents a p-value between .05 and .1 .

The first row indicates whether the data set being used is the extended data set or the primary data set and whether the broad or narrow definition of syndication is used. The second row shows the coefficient associated with the dummy variable for syndication. This coefficient is an estimate of the net value of syndication arising from the positive influence of the value-added effect and the negative influence of the selection effect. The narrow syndication dummy variable in the extended data set is not quite significant at the $10 \%$ level. However, the overall pattern is consistent with the t-tests on the means and confirms that syndicated investments tend to have higher returns than stand-alone investments.

The computer and communications sector did well compared to other sectors and this is a

\footnotetext{
ix Since we use industry dummies to predict holding periods to construct the extended data set, the reader might prefer to focus on the primary data set for this analysis.
} 
significant effect. Also, as one would expect, the tax-advantaged funds had lower rates of return than the others. This makes sense because the tax-advantaged funds offer tax advantages to underlying investors in the venture fund and therefore require a lower threshold return for their investors than do other funds. However, the apparent size of this effect is larger than might be expected.

\section{$\underline{6.3 \text { Correcting for Other Factors }}$}

There are other factors that might be important in determining returns. In particular, we might anticipate scale effects if either economies of scale or capital constraints induce an apparent advantage from size. If syndicated investments give rise to larger ventures, then perhaps it is scale rather than syndication that explains differences in returns. We might also expect the year of exit to be important (i.e. returns would be higher in good years than in bad) and we expect that the age of the venture might be important. It is possible to correct for all these factors. As it turns out, they are all insignificant and they do not affect the main findings concerning syndication, and this remains true for various permutations of specification. In the interest providing some insight into the performance of these variables we report the following results, incorporating all these effects.

Table 3: Other Possible Influences on Returns

Dependent variable $=$ Annual $\%$ rate of return; Syndication $=$ dummy variable

\begin{tabular}{||c|c|c|c|c||}
\hline data set & primary, narrow & primary, broad & extended, narrow & extended, broad \\
\hline syndication & $32.2(2.96)^{* * *}$ & $29.4(2.55)^{* *}$ & $20.0(2.07)^{* *}$ & $23.3(2.38)^{* *}$ \\
\hline computer industry & $35.6(3.03)^{* * *}$ & $30.8(2.62)^{* *}$ & $38.3(3.75)^{* * *}$ & $34.5(3.39)^{* * *}$ \\
\hline pref. tax status & $-35.0(2.08)^{* *}$ & $-35.6(2.11)^{* *}$ & $-42.0(3.21)^{* * *}$ & $-42.3(3.25)^{* * *}$ \\
\hline log (age) & $-6.1(0.89)$ & $-6.3(0.91)$ & $0.07(0.01)$ & $0.07(0.01)$ \\
\hline employment & $.0025(0.20)$ & $-.004(0.33)$ & $-.008(0.69)$ & $-.006(0.49)$ \\
\hline 1993 & $13.4(0.31)$ & $18.7(0.43)$ & $27.2(1.01)$ & $32.0(1.19)$ \\
\hline 1994 & $-20.3(0.47)$ & $-16.3(0.37)$ & $15.9(0.61)$ & $20.0(0.77)$ \\
\hline 1995 & $11.5(0.27)$ & $12.2(0.29)$ & $21.9(0.86)$ & $24.0(0.95)$ \\
\hline 1996 & $38.7(0.97)$ & $38.2(0.96)$ & $34.4(1.38)$ & $37.1(1.48)$ \\
\hline 1997 & $18.8(0.49)$ & $20.8(0.53)$ & $18.4(0.78)$ & $22.2(0.95)$ \\
\hline 1998 & $26.12(0.42)$ & $32.1(0.51)$ & $32.0(0.59)$ & $36.3(0.67)$ \\
\hline const & $3.3(0.08)$ & $0.3(0.01)$ & $-2.5(0.09)$ & $-10.2(.37)$ \\
\hline \# obs & 260 & 260 & 349 & 349 \\
\hline
\end{tabular}




\begin{tabular}{||c|c|c|c|c||}
\hline adj. $\mathrm{R}^{2}$ & 0.07 & 0.06 & 0.06 & 0.06 \\
\hline
\end{tabular}

t-statistics are in parentheses. $* * *$ represents a p-value of .01 or less, $* *$ represents a p-value between .01 and .05 , and $*$ represents a p-value between .05 and .1 .

Some of the new included variables have missing data. We are therefore forced to drop some observations, leading to fewer observations than in the corresponding regressions reported in Table 2 . One of the additional control variables is age of the venture in years, measured as the time from business formation, which may precede incorporation. Most ventures are young, but there are some ventures that are relatively old as firms can sometimes exist for a long time before seeking venture capital financing, especially for "turnaround" and LBO investments. About 10\% of the ventures in the data set report an age of 20 years or more. Because the distribution of age is skewed to the right we use the natural log of age. This variable is, however, insignificant. The estimated absolute effect of log (age) is small and the standard errors are relatively large. Using raw (i.e. unlogged) age yields even less significant results and does not affect the coefficients on the other variables.

The regressions shown in Table 3 use the variable "employment" (measured by the number of employees in the venture). This is supposed to capture the size or scale of the venture. Employment is not an ideal measure of size, as it does not directly capture the amount of physical capital or other factors that contribute to total productive capacity. However, for most relatively young small private companies, the major expense and the major asset is the employees, so employment should capture an important element of scale. We have another variable that reflects size, which is the total investment in the venture by all venture capitalists. These two measures of scale have a significant positive correlation coefficient of 0.37 , suggesting that they are both capturing some underlying size concept, but also suggesting that they might be capturing some different aspects of scale as well. However, regardless of whether we include one or the other or both of these variables, the scale effect is not significant, the syndication effect is significant, and the estimates and significance of syndication are only marginally affected.

The other factor we correct for is timing of the exit, using dummy variables to represent the year of exit. (The base year is 1992.) These dummy variables are insignificant, although the absolute level of returns does vary substantially on average from year to year. However, the variation across ventures is 
large compared to the variation over time. We tried using a time trend (not reported) without finding significant results, but it is clear from the pattern of the dummy variables that a time trend would not capture much. We also tried using a variable to capture the state of business cycle, which also was not significant. There are other variables that might serve as controls ${ }^{\mathrm{x}}$, but after substantial amounts of specification testing we concluded that the syndication effect is robust, as are the tax-status effect and the computer industry effect.

\section{$\underline{6.4 \text { Degrees of Syndication }}$}

So far we have treated syndication as a dummy variable - either syndication occurs or it does not occur. However, it is possible to treat syndication more finely, as we know the number of syndicating venture capitalists associated with each venture. Of the 584 exits in the data set, 341 are stand-alone, 108 involve two venture capitalists, 59 involve three venture capitalists, 28 involve 4 venture capitalists, etc. Table 4 reports the results of a regression similar to equation (10) except that we use the number of syndicating venture capitalists rather than just a syndication dummy variable. The results are as follows. Table 4: Effect of the degrees of syndication on returns Dependent variable $=$ annual rate of return; \# of vcs $=$ count

\begin{tabular}{||c|c|c|c|c|c|c||}
\hline \hline Regression & \# of vcs & COMP & PTS & Const. & \# obs & adj. $\mathrm{R}^{2}$ \\
\hline \hline primary, broad & $8.42(2.97)^{* * *}$ & $24.4(2.41)^{* *}$ & $-26.8(1.90)^{*}$ & $4.1(0.49)$ & 389 & 0.05 \\
\hline extended, broad & $6.50(2.55)^{* *}$ & $26.3(3.13)^{* * *}$ & $-29.6(3.05)^{* * *}$ & $10.6(1.57)$ & 584 & 0.05 \\
\hline
\end{tabular}

${ }^{x}$ Two other variables in the data set that might have been used as controls are mode of exit and location. The problem with mode of exit is that it is endogenous in that the success of the venture largely determines the mode of exit. Successful ventures lead to ventures in the form of IPOs and acquisitions. Less successful ventures normally lead to management buyouts or secondary sales, and the least successful ventures lead to write-offs. Thus exit type is largely determined by the returns and should not be included as an explanatory variable for returns in an ordinary least squares regression. The problem with using location of the venture as an explanatory variable is that location is largely insignificant except for one effect - Quebec. However, it is primarily Quebec venture capitalists who have preferential tax status, so including location would induce collinearity with the tax status variable. Our judgement is that it is tax status effect that is fundamental, not location per se, so we do not correct for location. 
$\mathrm{t}$-statistics are in parentheses. $* * *$ represents a p-value of .01 or less, $* *$ represents a p-value between .01 and .05 , and * represents a p-value between .05 and .1 .

We use only the broad definition of syndication in Table 4 as there is some ambiguity about exactly how the counts should be done for the narrow definition. For example, the appropriate classification if two venture capital investments are simultaneous and one more is pre-existing is not obvious. In any case, Table 4 indicates that a larger number of venture capitalists is associated with increased returns, as we would expect from the value-added hypothesis.

Table 4 suggests that value is increasing in the number of venture capitalists. There is insufficient evidence to suggest whether this effect might be subject to either increasing or decreasing returns. When we introduce a quadratic term (the number of venture capitalists squared), the extra term is insignificant and the adjusted $\mathrm{R}^{2}$ falls. Similarly, if we use the $\log$ of the number of venture capitalists instead of the raw number, the adjusted $\mathrm{R}^{2}$ falls and the significance of the explanatory variable is slightly reduced. In short, there is very little evidence to suggest that the relationship is anything other than linear, although there is insufficient data to place much weight on this finding regarding functional form.

\section{The Risk Sharing and Scale Hypotheses}

In this paper we focus on two competing and possibly complementary rationales for syndication: selection and value-added, and we assume that venture capitalists are risk neutral. However, it is also plausible that risk-aversion might be a motive for syndication, as venture capitalists might seek to share the risk associated with a particular venture. Equivalently, we might say that by syndicating a particular venture capitalist is able to invest in more ventures, given the size of its pool of investment capital, and thus achieve (potentially) greater diversification.

Furthermore, as pointed out by a referee, it might be difficult to distinguish between the risksharing hypothesis and the value-added hypothesis. Depending on the joint distribution of risk and return across the population of available investments and on the precise specification of the venture capitalists' attitudes toward risk, it is possible that we could observe a set of high-risk, high-return syndicated ventures. This could induce a higher ex-post return for syndicated ventures. Thus risk sharing is an alternative explanation for the results of Section 6 . 
It is difficult to test the importance of risk sharing. The relevant risk consideration from the venture capitalist's point of view is the contribution of a given investment to the overall portfolio risk, and this depends on the investment's entire covariance structure vis-à-vis other investments in the venture capitalist's portfolio, including the various investments that are not in our data set. However, if the total contribution of an investment to the venture capitalist's risk is correlated with its own variance, then we might expect a risk sharing motive to cause syndicated investments to exhibit more variability than standalone investments, as venture capitalists would seek syndication over more risky investments so as to allow themselves more diversification. Syndicated investments do have higher variability in our data. The returns to syndicated investments (broad definition) have a standard deviation of 100.2, while the standard deviation of stand-alone investments is 80.3. Using a variance ratio test for the difference of standard deviations, this difference is significant at the $1 \%$ level, suggesting that risk sharing might be a plausible partial explanation for syndication.

Another relevant piece of information concerns the size of a typical investment, relative to the size of a typical venture capitalist. We would expect that risk aversion is likely to be more important if the capital requirements of a venture are large compared to the resources of the interested venture capitalists. The size measure we have for a venture is investment in the venture by venture capitalists in the data set. The size measure we have for venture capitalists is their total investments recorded in the data set. As many venture capitalists have substantial "passive" investments (treasury bills, money market investments, etc.) and have investments in other countries or in other types of assets as well, this is likely to significantly understate the size of the venture capitalist. In addition, many venture capitalists are subsidiaries of much larger financial institutions. However, using our limited definition of size, the following table shows the mean and several percentiles of the size distribution for ventures and for venture capitalists.

Table 5: Size in C\$million (1997 dollars)

\begin{tabular}{|l|r|r|r|r|r||}
\hline & \multicolumn{1}{|c|}{ Mean } & \multicolumn{1}{|c|}{$20^{\text {th }}$ percentile } & \multicolumn{1}{c|}{ Median } & $80^{\text {th }}$ percentile & \multicolumn{1}{c|}{ Number } \\
\hline \hline Ventures & 2.74 & 0.27 & 1.04 & 3.99 & 2889 \\
\hline Venture Capitalists & 40.92 & 4.97 & 15.66 & 67.09 & 114 \\
\hline
\end{tabular}


The table includes all venture capitalists with 5 or more investments in the data set. These venture capitalists account for $94 \%$ of all investments. The other venture capitalists would consist mostly of investors who are primarily invested in other countries or in areas other than venture capital. This table covers all 2889 ventures in the data base, not just those where exits have occurred. The table shows that typical ventures are small compared to typical venture capitalists, and this effect would be stronger if we had the total financial portfolio of venture capitalists. However, the larger ventures are significant in size relative to the smaller venture capitalists, so this table would not rule out the possibility of risk aversion playing a significant role for some investments.

Our informal discussions with practitioners suggest that venture capitalists, of all financial intermediaries, seem most conscious of being willing to take risks. Still we recognize that risk sharing might play a significant role. Collusion would also offer an explanation as to why syndicated returns are higher. However, we can at least still infer that the selection effect is NOT the major factor in determining the pattern of relative returns to stand-alone and syndicated ventures.

Table 5 also sheds light on whether capital constraints might play a role in syndication. Syndication is more likely to occur in cases where a single venture capitalist is not large enough to fully finance the venture capital needs of a particular venture. Considering that scale effects are not significant in explaining venture capital returns, the capital constraint effect would seem unlikely to bias the pattern of returns in favor of syndicated investments, so it is less of a concern than risk sharing. Still it is useful to know if capital constraints are important. Table 5 does not rule out capital constraints being important in some cases, but such constraints would rarely be an issue for the larger venture capitalists who do most venture capital investing.

One other data-related point to consider is that a project that provides above-normal returns for a longer period is better than a project that provides the same annual rate of return for a shorter period. Arguably one might use the total above-normal return rather than the annualized rate of return as the dependent variable. However, using plausible values for the normal rate of return, the estimated results are very similar to those for annual rates of return.

\section{Concluding Remarks}

In this paper we provide formal representations of two hypotheses concerning the motivation for 
venture capital syndication. One hypothesis, which we refer to as the "selection" hypothesis, is that venture capitalists syndicate in order to obtain a "second opinion" about the quality of a particular investment under consideration. We show that this hypothesis implies that rates of return should, other things equal, be lower for syndicated investments than for stand-alone investments. The reason is that a second opinion is only needed on marginal investments. Projects that are obviously good can proceed without a second opinion. Therefore, stand-alone projects should exhibit the highest returns ex post.

The alternative hypothesis, which we label the "value-added" hypothesis, is that syndication adds value to a given project. This implies that syndicated projects should have higher rates of return than stand-alone projects. The comparison between the selection hypothesis and the value-added hypothesis goes to the heart of the fundamental question as to what venture capitalists actually do. Do venture capitalists add value to projects or do they merely select the more promising projects?

Our analysis clearly favors the value-added hypothesis, as syndicated projects have, on average, higher rates of return than stand-alone projects. The paper reports t-tests of the difference between two means and regression analysis, and the main result is clear despite the modest size of our data set. The positive effect of syndication is significant in both the economic and the statistical sense. ${ }^{\mathrm{xi}}$ We also report our attempt to control for several variables that might be expected to affect the regression. We also tried but do not report other specifications.

Our empirical analysis does not imply that the value of a "second opinion" in making selections is absent. It merely means that the value-added effect is empirically stronger than the selection effect. Thus our analysis suggests that venture capitalists do much more than just select promising projects; they also add value through management or other activities. Our analysis does rely on specific assumptions. In particular, we assume that the lead venture capitalist makes the syndication decision. Thus the syndication decision is endogenous to the lead venture capitalist but exogenous to the venture. The models could have

\footnotetext{
xi The value-added hypothesis would be further supported if we could demonstrate empirically that syndicating venture capitalists have complementary skills relative to lead venture capitalists, but we do not have appropriate variables in the data to test this idea.
} 
different implications if the venture (i.e. the entrepreneur) made this decision.

We also consider the role of risk aversion and risk-sharing, as this might be an alternative explanation for the high returns to syndicated investments. We conclude that risk sharing might be important in some cases, but we do not have enough evidence to draw clear conclusions. Even if risk sharing is an important factor, however, we can still safely conclude that the selection effect is dominated by other considerations. 


\section{References}

Admati, A. and P. Pfleiderer, 1994, Robust Financial Contracting and the Role of Venture Capitalists, Journal of Finance, 49, 371-402.

Amit, R., J. A. Brander, and C. Zott, 1998, Why do Venture Capital Firms Exit? Theory and Canadian Evidence, Journal of Business Venturing, 16, 441-466.

Gompers, P. A., 1995, Optimal Investment, Monitoring, and the Staging of Venture Capital, Journal of Finance, 50, 1461-1489.

Hellmann, T.A., 1998, The Allocation of Control Rights in Venture Capital Contracts, Rand Journal of Economics, 29, 57-76.

Hellmann, T. and M. Puri, 2000, The Interaction Between Product Market and Financing Strategy: the Role of Venture Capital, Review of Financial Studies, 13, 959-984.

Hellmann, T. and M. Puri, 2002, Venture Capital and the Professionalization of Start-up Firms: Empirical Evidence, Journal of Finance, forthcoming.

Gorman, M. and W. A. Sahlman, 1989, What do Venture Capitalists do, Journal of Business Venturing, 4, 231-248.

Kaplan, S. and P. Strömberg, 1999, Financial Contracting Meets the Real World: an Empirical Study of Venture Capital Contracts, working paper, University of Chicago.

Kunze, R. J., 1990, Nothing Ventured: the Perils and Payoffs of the Great American Venture Capital Game, New York: Harper Collins.

Lerner, J., 1994, The Syndication of Venture Capital Investments, Financial Management, 23, 16-27.

Megginson, W. C. and K. A. Weiss, 1991, Venture capital certification in initial public offerings, Journal of Finance, 46, 879-93.

Perez, R.C., 1986, Inside Venture Capital: Past, Present, and Future, New York: Praeger.

Sah, R. K. and J.E. Stiglitz, 1986, The Architecture of Economic Systems: Hierarchies and Polyarchies, American Economic Review, 76, 716-727.

Schilit, W. K., 1991, Dream Makers and Deal Breakers: Inside the Venture Capital Industry (PrenticeHall, Englewood Cliffs, New Jersey). 


\section{Appendix: Proofs of Propositions}

\section{Proof of Proposition 3:}

ia) (sufficiency) First we prove the "if" part: that the conditions $\mathrm{R}>\mathrm{r}$ and $\mathrm{N}=0$ are jointly sufficient for stand-alone investment. If $\mathrm{R}>\mathrm{r}$, then stand-alone investment is preferred to rejection as $*_{21}$ is positive. If, in addition, $\mathrm{N}=0$, then $*_{32}<0$, which implies that stand-alone investment is preferred to syndication. Thus stand-alone investment is the dominant strategy.

ib) (necessity) We now prove the "only if" part (i.e. that each condition is strictly necessary for standalone investment). If $\mathrm{R} \# \mathrm{r}$ then rejection is preferred to stand-alone investment. (Recall that rejection is assumed to be chosen in the event of ties (i.e. if $2=r$ ).) Thus $R>r$ is necessary for stand-alone investment. Furthermore, if $\mathrm{N}=\mathrm{v}$, then condition (6) implies that ${ }_{32}$ as given by (9) is positive in which case syndication would be preferred to stand-alone investment. Thus $\mathrm{N}=0$ is also necessary for stand alone investment.

iia) (sufficiency) The two conditions are jointly sufficient for syndication. Syndication will be chosen if $*_{31}$ and $*_{32}$ as given by (8) and (9) are positive. $*_{31}$ is clearly positive if $\mathrm{N}=\mathrm{v}$ and $\mathrm{R}>\mathrm{r}-\mathrm{v}$. This means that the value of syndication exceeds the value of rejection. In addition, if $\mathrm{N}=\mathrm{v}$, then condition (6) implies that $*_{32}>0$, so syndication is also preferred to stand-alone investment. iib) (necessity) If $\mathrm{N} \ldots \mathrm{v}$, then it must equal 0 . If $\mathrm{N}=0$ it follows from (8) and (9) that either $*_{31}$ must be nonpositive or $*_{32}$ must be negative. (If $\mathrm{R}>\mathrm{r}$ then $*_{32}$ would be negative, while if $\mathrm{R} \# \mathrm{r}$, then $*_{31}$ would be nonpositive.) Thus syndication could not be chosen. $\mathrm{N}=\mathrm{v}$ is therefore necessary for syndication. If $\mathrm{R} \# \mathrm{r}$ - v then $*_{31}$ as given by (8) cannot be positive (regardless of the value of $\mathrm{N}$ ) and syndication cannot be chosen. Thus $\mathrm{R}>\mathrm{r}-\mathrm{v}$ is also necessary.

iii) This follows immediately from parts i) and ii) and completes the proof.***

\section{Proof of Proposition 4:}

We refer to stand-alone investment as event T. Similarly, we refer to the event that syndication is chosen as event $\mathrm{Y}$. We now calculate the expected value of expected payoff $\mathrm{R}$ for stand-alone investment, which is denoted $\mathrm{E}(\mathrm{R} \mid \mathrm{T})$. This expectation is given by

$$
\mathrm{E}(\mathrm{R} \mid \mathrm{T})=\ln \mathrm{f}(\mathrm{R} \mid \mathrm{T}) \mathrm{dR}(\mathrm{A} 1)
$$


The unconditional distribution of $\mathrm{f}$ is, by assumption, uniform on the interval $\left[0, \mathrm{R}^{*}\right]$. From Proposition 3 , part $i$, syndication occurs if and only if $R>r$ and $v=0$. It follows that $f(R \mid T)$ is uniform on the interval $\left(\mathrm{r}, \mathrm{R}^{*}\right]$. Therefore

$$
\mathrm{E}(\mathrm{R} \mid \mathrm{T})=\left(\mathrm{r}+\mathrm{R}^{*}\right) / 2
$$

We now need to calculate the expected rate of return on syndicated investments. This requires finding $\mathrm{E}(\mathrm{R}+\mathrm{N} \mid \mathrm{Y})$, which can be written

$$
\mathrm{E}(\mathrm{R}+\mathrm{N} \mid \mathrm{Y})=\mathrm{E}(\mathrm{R} \mid \mathrm{Y})+\mathrm{E}(\mathrm{N} \mid \mathrm{Y})(\mathrm{A} 3)
$$

where $E(N \mid Y)=v$, because syndication can occur only if it adds value. To find $E(R \mid Y)$ we note from Proposition 3 that, given $N=v, Y$ (syndication) occurs if and only if $R>r-v$. As $f(R)$ is uniform it follows that the expected value of $R$ over the relevant range $\left(r-v, R^{*}\right]$ is $\left(R^{*}+r-v\right) / 2$. Substituting these values for $\mathrm{E}(\mathrm{N} \mid \mathrm{Y})$ and $\mathrm{E}(\mathrm{R} \mid \mathrm{Y})$ into $(\mathrm{A} 3)$ yields

$$
\mathrm{E}(\mathrm{R}+\mathrm{N} \mid \mathrm{Y})=\left(\mathrm{R}^{*}+\mathrm{r}-\mathrm{v}\right) / 2+\mathrm{v}(\mathrm{A} 4)
$$

The expected cash flow (to the syndicate) from syndication is given by (A4) and the expected cash flow from stand-alone investment is given by (A2). This difference, denoted ) R, is

$$
\text { ) } \mathrm{R}=\left(\mathrm{R}^{*}+\mathrm{r}-\mathrm{v}\right) / 2+\mathrm{v}-\left(\mathrm{R}^{*}+\mathrm{r}\right) / 2=\mathrm{v} / 2>0 .
$$


ENDNOTES 